\title{
Article \\ Effects of Annealing on Enthalpy Recovery and Nanomechanical Behaviors of a La-Based Bulk Metallic Glass
}

\author{
Ting Shi ${ }^{1}$, Lanping Huang ${ }^{2}$ and Song $\mathrm{Li}^{1, * \mathbb{D}}$ \\ 1 State Key Laboratory for Powder Metallurgy, Central South University, Changsha 410083, China; \\ 183311045@csu.edu.cn \\ 2 Science and Technology on High Strength Structural Materials Laboratory, Central South University, \\ Changsha 410083, China; christie@csu.edu.cn \\ * Correspondence: 1s2011s1@csu.edu.cn; Tel.: +86-0731-88830911
}

Citation: Shi, T.; Huang, L.; Li, S. Effects of Annealing on Enthalpy Recovery and Nanomechanical Behaviors of a La-Based Bulk Metallic Glass. Metals 2021, 11, 579. https:// doi.org/10.3390/met11040579

Academic Editor: Alberto Moreira Jorge Junior

Received: 8 March 2021

Accepted: 26 March 2021

Published: 1 April 2021

Publisher's Note: MDPI stays neutral with regard to jurisdictional claims in published maps and institutional affiliations.

Copyright: (c) 2021 by the authors. Licensee MDPI, Basel, Switzerland. This article is an open access article distributed under the terms and conditions of the Creative Commons Attribution (CC BY) license (https:/ / creativecommons.org/licenses/by/ $4.0 /)$.

\begin{abstract}
Structural relaxation and nanomechanical behaviors of $\mathrm{La}_{65} \mathrm{Al}_{14} \mathrm{Ni}_{5} \mathrm{Co}_{5} \mathrm{Cu}_{9.2} \mathrm{Ag}_{1.8}$ bulk metallic glass (BMG) with a low glass transition temperature during annealing have been investigated by calorimetry and nanoindentation measurement. The enthalpy release of this metallic glass is deduced by annealing near glass transition. When annealed below glass transition temperature for $5 \mathrm{~min}$, the recovered enthalpy increases with annealing temperature and reaches the maximum value at $403 \mathrm{~K}$. After annealed in supercooled liquid region, the recovered enthalpy obviously decreases. For a given annealing at $393 \mathrm{~K}$, the relaxation behaviors of La-based BMG can be well described by the Kohlrausch-Williams-Watts (KWW) function. The hardness, Young's modulus, and serrated flow are sensitive to structural relaxation of this metallic glass, which can be well explained by the theory of solid-like region and liquid-like region. The decrease of ductility and the enhancement of homogeneity can be ascribed to the transformation from liquid-like region into solid-like region and the reduction of the shear transition zone (STZ).
\end{abstract}

Keywords: bulk metallic glasses; structure relaxation; enthalpy recovery; nanoindentation; annealing

\section{Introduction}

Bulk metallic glasses (BMGs) have attracted much attention owing to their excellent strength, high elastic limit, and outstanding soft magnetic properties [1-4], which originate from its disordered structure [5-7]. Compared with thermodynamically stable crystalline counterparts, BMGs are in a high-energy metastable state and tend to relax to a stable state. This process, called structural relaxation, has no effect on non-crystalline nature [8]. However, during the relaxation process, the atoms inside the material obviously migrate to an equilibrium position and evolve into a more densely arranged amorphous structure, which can cause the variations in atomic distribution, electronic configuration, and short range ordering, further leading to changes in physical properties (diffusivity [9], Corrosion resistance [10], impact toughness [11], etc.). Therefore, the investigation on structural relaxation is of great significance for grasping thermal stability and mechanical properties of BMGs.

The annealing treatment is commonly used to eliminate the thermal history of amorphous alloys and induce its structural relaxation. For example, after being annealed at $350{ }^{\circ} \mathrm{C}$ for $12 \mathrm{~h}, \mathrm{Zr}_{55} \mathrm{Cu}_{30} \mathrm{Ni}_{5} \mathrm{Al}_{10}$ BMG undergoes obvious brittle fracture, and its fracture energy density is reduced by $75 \%$, which is consistent with the increase in the degree of ordered structure characterized by high resolution transmission electron microscopy (HRTEM) [12]. The prolonged annealing or high temperature annealing treatment easily leads to the crystallization of amorphous alloys [13,14]. The crystallinity of $\mathrm{Zr}_{68} \mathrm{Cu}_{8} \mathrm{Ni}_{8} \mathrm{Al}_{16}$ BMG increases as the annealing temperature rises, but its mechanical properties gradually decrease [15]. It has been reported that when the crystallinity of this Zr-based BMG annealed at $713 \mathrm{~K}$ is $77 \%$, the plastic strain drops sharply to zero [15]. Otherwise, lots 
of investigations have indicated that the structural relaxation of amorphous alloys could lead to the annihilation of free volume and the loss of plasticity $[11,16,17]$. However, Shi et al. have found that the plasticity of $\mathrm{Zr}_{59} \mathrm{Ti}_{6} \mathrm{Cu}_{17.5} \mathrm{Fe}_{10} \mathrm{Al}_{7.5} \mathrm{BMG}$ reaches as high as $12.1 \%$ after a short time annealing at $200{ }^{\circ} \mathrm{C}$ [18]. It has also been reported that the plasticity of $\mathrm{Zr}_{65} \mathrm{Cu}_{17.5} \mathrm{Al}_{7.5} \mathrm{Ni}_{10}$ BMG annealed at $573 \mathrm{~K}$ for $1 \mathrm{~h}$ increases to $7.1 \%$ due to the formation of 5-12 nm nanocrystals in amorphous matrix [19]. This is because the nanocrystalline particles precipitated in the amorphous matrix helps to generate shear bands and suppress crack propagation during deformation.

La-based amorphous alloys have excellent glass-forming ability (GFA) and low glass transition temperature $\left(T_{g}\right)$ [20], which can induce relaxation at relatively low temperature. When the annealing temperature is lower than $T_{g}$, the $\alpha$ relaxation involving more atoms is frozen, and the local atoms at the nanoscale move cooperatively to cause $\beta$ relaxation. It has been reported that the slow $\beta$ relaxation amplitude decreases while the activation energy increases in $\mathrm{La}_{30} \mathrm{Ce}_{30} \mathrm{Al}_{15} \mathrm{Co}_{25} \mathrm{BMG}$ annealed below $T_{g}$ [21]. Liang et al. have found that a La-based BMG can promote the local atomic rearrangement ( $\beta$ relaxation) after being annealed for a short time at a high temperature close to $T_{g}$ by dynamic mechanical analysis [22]. Cui et al. have investigated compressive properties of $\left(\mathrm{La}_{25} \mathrm{Ce}_{75}\right)_{65} \mathrm{Al}_{11} \mathrm{Co}_{24}$ $\mathrm{BMG}$ at $233 \mathrm{~K}$ and $300 \mathrm{~K}$, respectively [23], and found that this BMG shows obvious brittle fracture at $233 \mathrm{~K}$, but excellent plasticity at $300 \mathrm{~K}$, suggesting that the activation of $\beta$ relaxation is temperature-dependent. Currently, the work on the relationship between the microstructure and nanomechanical properties of La-based BMGs after annealing is relatively scarce. Therefore, in this work, the effects of isochronous annealing and isothermal annealing on the structural relaxation and thermal stability of a La-Al-Ni-Co$\mathrm{Cu}-\mathrm{Ag}$ BMG have been analyzed by differential scanning calorimetry (DSC). The influence of annealing temperature on nanomechanical properties has been investigated by using nanoindentation and atomic force microscope (AFM).

\section{Experimental}

Under the protection of purified argon atmosphere, the ingot with a nominal composition of $\mathrm{La}_{65} \mathrm{Al}_{14} \mathrm{Ni}_{5} \mathrm{Co}_{5} \mathrm{Cu}_{9.2} \mathrm{Ag}_{1.8}$ was prepared by arc-melting a mixture of pure $\mathrm{La}, \mathrm{Al}, \mathrm{Ni}$, $\mathrm{Co}, \mathrm{Cu}$, and Ag elemental metals (all $99.9 \mathrm{wt} \%$ purity), which were provided by ZhongNuo Advanced Material (Beijing, China) Technology Co., Ltd. In order to ensure the uniformity of the microstructure, each ingot was re-melted 5 times. Cylindrical rods having a diameter of $5 \mathrm{~mm}$ and a length of $60 \mathrm{~mm}$ were obtained by tilt-casting into a copper mold under argon atmosphere. The outer appearance of the cylindrical rod is shown in Figure 1. The as-cast rods were sliced to guarantee that each sample had a thickness of about $0.8 \mathrm{~mm}$ and a mass of about $40 \mathrm{mg}$. The annealing treatment was carried out by a Perkin Elmer- 8000 DSC (Waltham, MA, USA) at a heating rate of $20 \mathrm{~K} / \mathrm{min}$ under nitrogen atmosphere. To optimize the best annealing temperature, various holding temperatures near $T_{g}$ have been used to treat the as-cast La-based BMG with fixed time ( $5 \mathrm{~min})$. The isochronous annealing treatments at various temperatures were conducted at 373, 383, 393, 403, 413, 423, and $433 \mathrm{~K}$ for $5 \mathrm{~min}$, respectively. Based on the observed enthalpy recovery in DSC curve, the isothermal annealing temperature was set to be $393 \mathrm{~K}$ and the annealing time were 10,60, 120 , and $240 \mathrm{~min}$, respectively. The as-cast and annealed samples were tested using a Japan $\mathrm{D} / \mathrm{max} 2500$ PC X-Ray diffractometer (XRD) equipped with $\mathrm{Cu}-\mathrm{K} \alpha$ radiation to investigate the microstructural stability (Rigaku Corporation, Tokyo, Japan). Thermal stability was investigated using a Perkin Elmer-8000 DSC (Waltham, MA, USA) from $323 \mathrm{~K}$ to $573 \mathrm{~K}$ at a heating rate of $20 \mathrm{~K} / \mathrm{min}$ under nitrogen atmosphere. Nanoindentation experiments were performed using a Switzerland UNHT nanoindenter with a Berkovich indenter under a load-control mode (CSM Instruments, Peseux, Switzerland). Each sample was tested 5 times. Indentation morphologies were examined by a USA 5500 AFM. The microhardness was tested by a HV-1000Z (CN) microhardness tester (FengZhi Instrument, Jinan, China) at a load of $20 \mathrm{~g}$ and a holding time of $10 \mathrm{~s}$, respectively. 


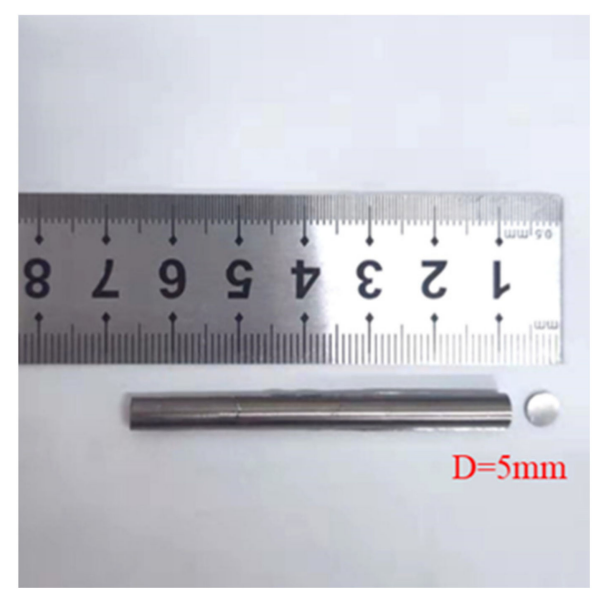

Figure 1. Outer appearance of $\mathrm{La}_{65} \mathrm{Al}_{14} \mathrm{Ni}_{5} \mathrm{Co}_{5} \mathrm{Cu}_{9.2} \mathrm{Ag}_{1.8}$ bulk metallic glass (BMG) rod with a diameter of $5 \mathrm{~mm}$.

\section{Results and Discussion}

The behaviors of glass transition and crystallization of the as-cast $\mathrm{La}_{65} \mathrm{Al}_{14} \mathrm{Ni}_{5} \mathrm{Co}_{5} \mathrm{Cu}_{9.2} \mathrm{Ag}_{1.8}$ BMG at the heating rate of $20 \mathrm{~K} / \mathrm{min}$ are shown in Figure 2. An obvious exothermic peak corresponding to crystallization process is found, which confirms the amorphous nature. The $T_{g}$ and onset crystallization temperature $T_{x}$ are determined to be $405 \mathrm{~K}$ and $449 \mathrm{~K}$, respectively. The inset in Figure 2 presents the XRD pattern of this BMG rod with a diameter of $5 \mathrm{~mm}$. The pattern exhibits the broad diffuse peak without any sharp crystalline peak, further certifying the fully amorphous structure of the sample.

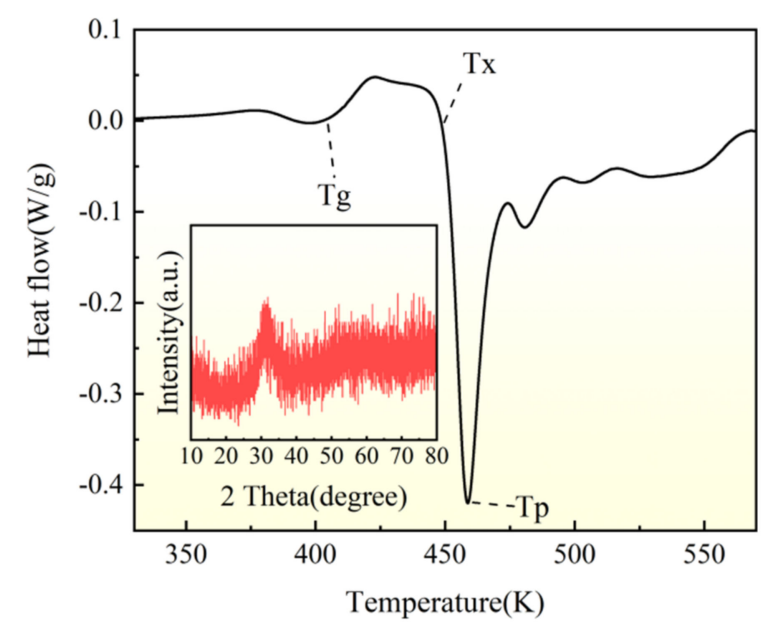

Figure 2. DSC curve and XRD pattern of $\mathrm{La}_{65} \mathrm{Al}_{14} \mathrm{Ni}_{5} \mathrm{Co}_{5} \mathrm{Cu}_{9.2} \mathrm{Ag}_{1.8} \mathrm{BMG}$ rod with a diameter of $5 \mathrm{~mm}$. The inset is the $X$-ray diffraction pattern.

Different temperatures ranging from 373 to $433 \mathrm{~K}$ are selected to investigate the nonisothermal enthalpy relaxation behavior of this BMG. Figure 3a shows the DSC curves of $\mathrm{La}_{65} \mathrm{Al}_{14} \mathrm{Ni}_{5} \mathrm{Co}_{5} \mathrm{Cu}_{9.2} \mathrm{Ag}_{1.8} \mathrm{BMG}$ rods annealed at different temperatures for $5 \mathrm{~min}$. The inset is the partially enlarged view of DSC curves near $T_{g}$. It can be found that the annealing near $T_{g}$ leads to the pronounced heat absorption corresponding to enthalpy recovery in the supercooled liquid region during the heating scanning after annealing and the magnitude of the heat absorption gradually increases with the increase of the annealing temperature below $T_{g}$. The enthalpy recovery process is obviously sensitive to the annealing temperature. It can be seen that the final magnitude of the endothermic overshoot decreases when the annealing temperature increases over $T_{g}$. The ordered degree of La-based BMG increases with the increase of the annealing temperature when it 
is annealed above $T_{g}$. This leads to the decrease of the energy state of the annealed sample.

Therefore, the magnitude of heat absorption decreases.
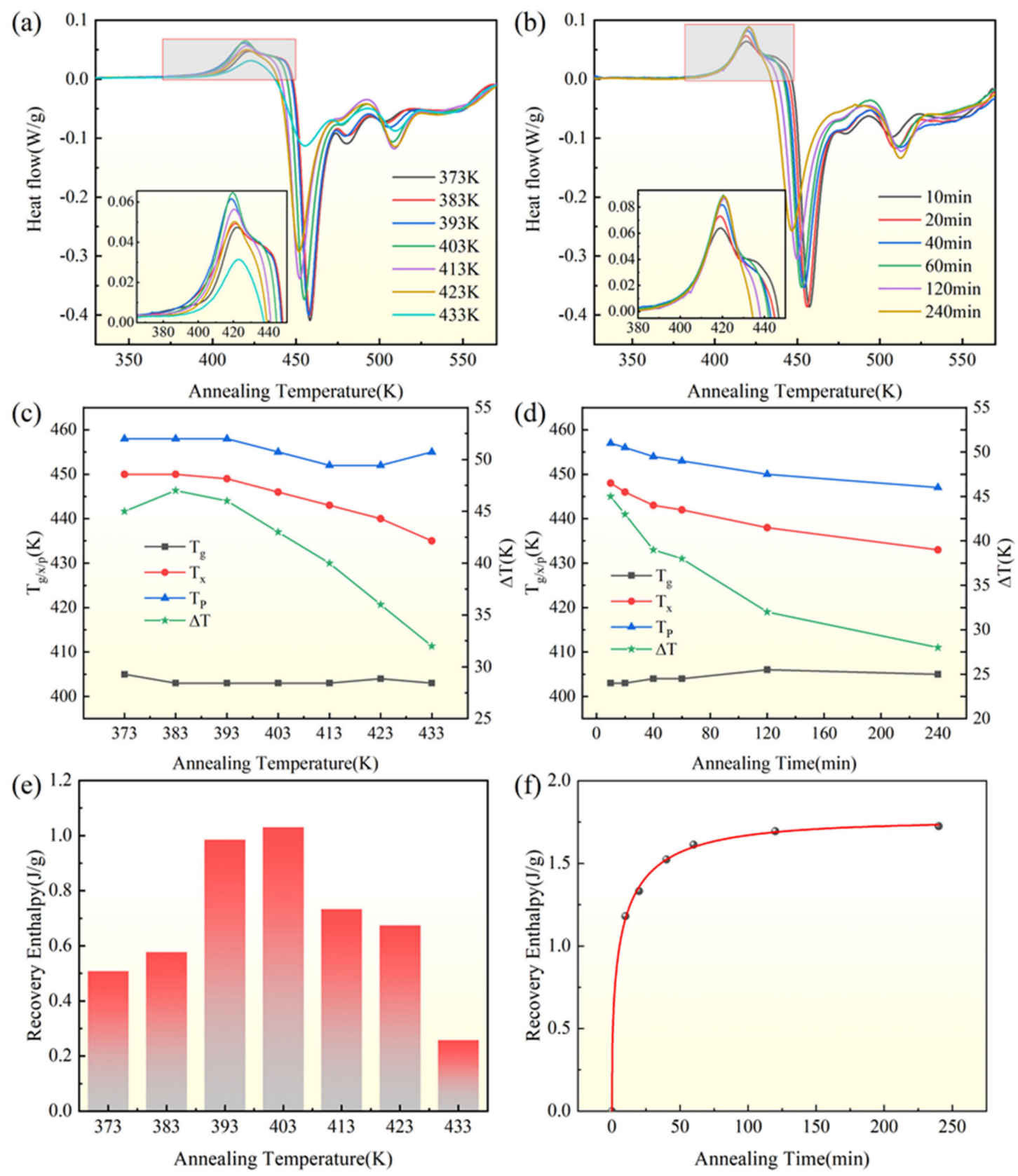

Figure 3. (a) DSC curves of $\mathrm{La}_{65} \mathrm{Al}_{14} \mathrm{Ni}_{5} \mathrm{Co}_{5} \mathrm{Cu}_{9.2} \mathrm{Ag}_{1.8} \mathrm{BMG}$ annealed at different temperatures for $5 \mathrm{~min}$; (b) DSC curves of $\mathrm{La}_{65} \mathrm{Al}_{14} \mathrm{Ni}_{5} \mathrm{Co}_{5} \mathrm{Cu}_{9.2} \mathrm{Ag}_{1.8}$ BMG annealed at $393 \mathrm{~K}$ for different time; (c) Dependence of thermal parameters of $\mathrm{La}_{65} \mathrm{Al}_{14} \mathrm{Ni}_{5} \mathrm{Co}_{5} \mathrm{Cu}_{9.2} \mathrm{Ag}_{1.8} \mathrm{BMG}$ annealed for $5 \mathrm{~min}$ on annealing temperature; (d) Dependence of thermal parameters of $\mathrm{La}_{65} \mathrm{Al}_{14} \mathrm{Ni}_{5} \mathrm{Co}_{5} \mathrm{Cu}_{9.2} \mathrm{Ag}_{1.8}$ BMG annealed at $393 \mathrm{~K}$ on annealing time; (e) Relationship between recovery enthalpy and annealing temperature; (f) Relationship between recovery enthalpy and annealing time as well as the solid line presenting a fitting curve by KWW function.

Figure $3 \mathrm{~b}$ shows the DSC curves of $\mathrm{La}_{65} \mathrm{Al}_{14} \mathrm{Ni}_{5} \mathrm{Co}_{5} \mathrm{Cu}_{9.2} \mathrm{Ag}_{1.8} \mathrm{BMG}$ rods annealed at $393 \mathrm{~K}$ for different times. The inset is the partially enlarged view of DSC curves near $T_{g}$. The variation of the magnitude of enthalpy recovery on annealing time is similar to that on annealing temperature. The magnitude of enthalpy recovery increases with the annealing time and eventually remains steady after being annealed for $240 \mathrm{~min}$. The variation of 
enthalpy recovery may be attributed to the denser microstructure formed by the diffusion and rearrangement of the atoms in liquid-like regions with extending annealing time. Furthermore, the energy barrier for the transition from glassy state to the supercooled liquid region rises, as a consequence of the reduction of free volume.

Figure $3 c$, d shows the variation of $T_{g}, T_{x}$, peak crystallization temperature $\left(T_{p}\right)$, and supercooled liquid region $\left(\Delta T, \Delta T=T_{x}-T_{g}\right)$. The values of $T_{g}$ are not significantly sensitive to the annealing temperature for a given annealing time. When the annealing temperature is lower than $T_{g}$, the $T_{x}$, and $T_{p}$ hardly change with the increase of annealing temperature, and the first crystallization peaks all almost coincide. When the annealing temperature is $403 \mathrm{~K}$ or above, the first crystallization peak shifts to the lower temperature (Figure 3a), and the $T_{x}, T_{p}$, and $\Delta T$ decrease, indicating that thermal stability of this La-based BMG is reduced when being annealed in the supercooled liquid region.

The relationship between recovery enthalpy and annealing temperature is illustrated in Figure 3e. The variation of recovery enthalpy on annealing can be interpreted based on the concept of solid-like regions and liquid-like regions in amorphous alloys [24]. As we know, the amorphous structure is heterogeneous at the nanoscale and the areas with close atomic arrangement can be regarded as solid-like regions, while the areas with sparse atomic arrangement can be regarded as liquid-like regions accompanying with more free volume. When the annealing temperature increases, the excess free volume decreases more rapidly, this helps to increase the proportion of solid-like region, resulting in the increase of the short-range order and the energy required for the transition from glass state to the supercooled liquid state. The concentration of the solid-like region is high enough at the annealing temperature above $403 \mathrm{~K}$, which may have a non-negligible interface interaction with the liquid-like zone [25]. This interaction at the interface may increase the energy of the system and further weaken the degree of enthalpy recovery.

Figure $3 f$ demonstrates that the recovery enthalpy evaluated from DSC curves can be well fitted by the Kohlrausch-Williams-Watts (KWW) function [26]:

$$
\Delta \mathrm{H}\left(\mathrm{T}_{\mathrm{a}}\right)=\Delta \mathrm{H}_{\mathrm{eq}}\left\{1-\exp \left[-\left(\mathrm{t}_{\mathrm{a}} / \tau\right)^{\beta}\right]\right\}
$$

where $T_{a}$ is the annealing temperature, $t_{a}$ is the annealing time, $\Delta H_{e q}$ is the value of relaxation enthalpy as $t_{a}$ approaches to infinity and $\tau$ is the average time of enthalpy relaxation. $\beta(0<\beta<1)$ is Kohlrausch exponent, which is inversely proportional to the distribution width of the relaxation time. The correlation coefficient $R^{2}$ of the fitted curve is 0.9992 , indicating a high degree of correlation and consistency with the experimental data. According to the fitted curve, the value of $\Delta \mathrm{H}_{\mathrm{eq}}$ is calculated to be $1.75 \mathrm{~J} / \mathrm{g}, \tau$ is $490 \mathrm{~s}$ and $\beta$ is 0.45 . The recovery enthalpy after annealing for $240 \mathrm{~min}$ is $1.73 \mathrm{~J} / \mathrm{g}$, which is similar to $\Delta \mathrm{H}_{\mathrm{eq}}$, manifesting that the annealing at $393 \mathrm{~K}$ for $240 \mathrm{~min}$ make this BMG close to the full relaxation state. Qiao et al. have investigated the dynamic relaxation behavior of CuZr-based BMG by mechanical spectroscopy and found that the value of $\beta$ of this BMG is about 0.5 , which is between 0.35 for polymers and 0.7 for oxide glasses [27]. The $\beta$ value of $(\mathrm{LaCe})_{32.5} \mathrm{Co}_{20} \mathrm{Al}_{15} \mathrm{BMG}$ is also reported to be 0.463 [28], which is similar to the result of this work. However, the $\beta$ value of $\mathrm{La}_{65} \mathrm{Al}_{14} \mathrm{Ni}_{5} \mathrm{Co}_{5} \mathrm{Cu}_{9.2} \mathrm{Ag}_{1.8} \mathrm{BMG}$ is much lower than that of $\mathrm{Zr}_{55} \mathrm{Cu}_{30} \mathrm{Ni}_{5} \mathrm{Al}_{10} \mathrm{BMG}(0.69-0.78)$ [29], suggesting that the supercooled liquid in La-based BMG is more heterogeneous and shows the enhanced cooperativity of atomic rearrangement in comparison to Zr-based BMG.

The effects of the structural relaxation induced by annealing on micromechanical behaviors of $\mathrm{La}_{65} \mathrm{Al}_{14} \mathrm{Ni}_{5} \mathrm{Co}_{5} \mathrm{Cu}_{9.2} \mathrm{Ag}_{1.8}$ BMG have been investigated by nanoindentation method. Figure $4 \mathrm{a}$, b shows the typical load-depth curves for the as-cast and annealed $\mathrm{La}_{65} \mathrm{Al}_{14} \mathrm{Ni}_{5} \mathrm{Co}_{5} \mathrm{Cu}_{9.2} \mathrm{Ag}_{1.8} \mathrm{BMG}$ as well as the variations of the elastic modulus and hardness on annealing time. As shown in Figure $4 \mathrm{a}$, the depth caused by the same load decreases as the annealing time increases, indicating that the annealing leads to the hardening of La-based BMG. It is also confirmed by the measured microhardness of the as-cast and annealed La-based BMGs shown in Figure 4d. The microhardness of La-based BMG annealed 
for $240 \mathrm{~min}$ is $4.9 \%$ higher than that of the as-cast one. The similar phenomenon has been also confirmed in a Ti-based metallic glass [30]. The proportion of liquid-like region during relaxation decreases due to atom movement and the reduction of free volume. This leads to the enhancement of the bonding force between atoms. Otherwise, it can be seen from Figure $4 \mathrm{~b}$ that the elastic modulus of La-based BMG gradually decreases with extending annealing time. In order to evaluate the plastic deformation behaviors of La-based BMG, the concept of plasticity criterion $\left(\mathrm{R}_{\mathrm{W}}\right)$ is introduced [31,32]:

$$
\mathrm{R}_{\mathrm{W}}=\frac{\mathrm{h}_{\mathrm{f}}}{\mathrm{h}_{\max }}
$$

where $h_{f}$ is the residual depth after unloading and $h_{\max }$ is the maximum depth under loading. Figure $4 c$ shows the dependence of $R_{W}$ on annealing time in La-based BMG annealed at $393 \mathrm{~K}$. The calculated values of $\mathrm{R}_{\mathrm{w}}$ steeply drop with the annealing time, indicating the loss of the plasticity in the annealed La-based BMG.
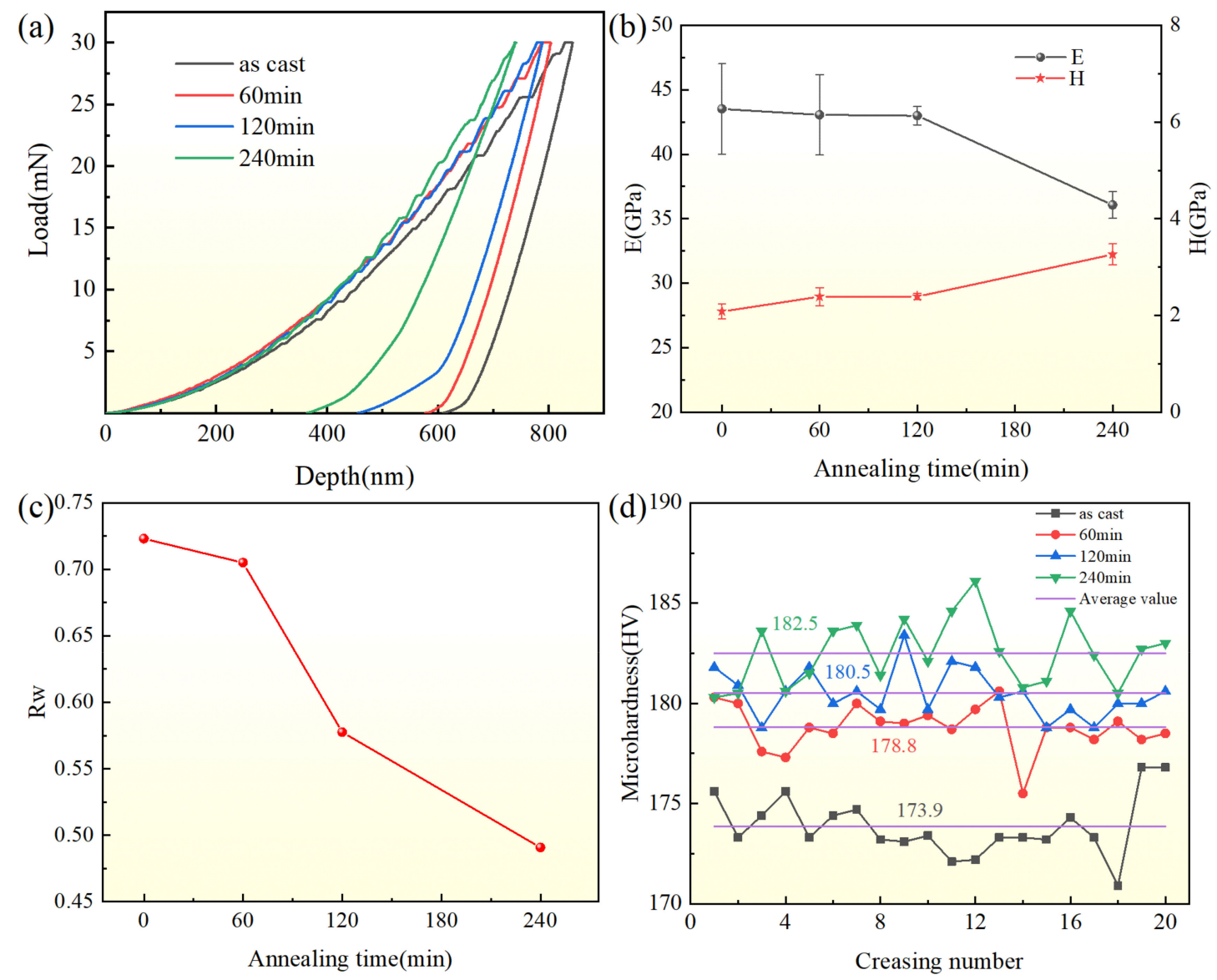

Figure 4. (a) Load-depth curves of $\mathrm{La}_{65} \mathrm{Al}_{14} \mathrm{Ni}_{5} \mathrm{Co}_{5} \mathrm{Cu}_{9.2} \mathrm{Ag}_{1.8} \mathrm{BMG}$ annealed at $393 \mathrm{~K}$ for different time; (b) Variations of elastic modulus (E) and hardness $(\mathrm{H})$ on annealing time; (c) Dependence of plasticity criterion $\left(\mathrm{R}_{\mathrm{W}}\right)$ on annealing time; (d) Microhardness of $\mathrm{La}_{65} \mathrm{Al}_{14} \mathrm{Ni}_{5} \mathrm{Co}_{5} \mathrm{Cu}_{9.2} \mathrm{Ag}_{1.8} \mathrm{BMG}$ annealed at $393 \mathrm{~K}$ for different time.

The characteristic of displacement mutation, also called serrated flow or pop-in, can be found in the load-depth curves for the as-cast and annealed La-based BMGs. In order to investigate the serrated flow behavior more intuitively, we use the following power law Equation (3) to fit the depth-load curve of the loading stage to obtain the baseline, and then subtract the baseline to get the relation curves based on the depth difference $\Delta \mathrm{h}$ and the load, as shown in Figure 5. The power law equation is introduced [33]:

$$
\mathrm{F}=\mathrm{ah}^{\mathrm{b}}
$$


where $\mathrm{F}$ is the load, $\mathrm{h}$ is the depth, $\mathrm{a}$ and $\mathrm{b}$ are the constants. The length of the serration can be measured by the difference between the peak value and the valley value, and the maximum value is $\Delta \mathrm{h}_{\max }$. The $\Delta \mathrm{h}_{\max }$ value of the sample annealed for $240 \mathrm{~min}$ is $12.2 \mathrm{~nm}$, which is $43 \%$ less than that of the as-cast one, and the $\Delta \mathrm{h}$ value of the sample annealed for $240 \mathrm{~min}$ fluctuates in a narrow range. This means that the long-time annealing improves the degree of structural heterogeneity in La-based BMG.
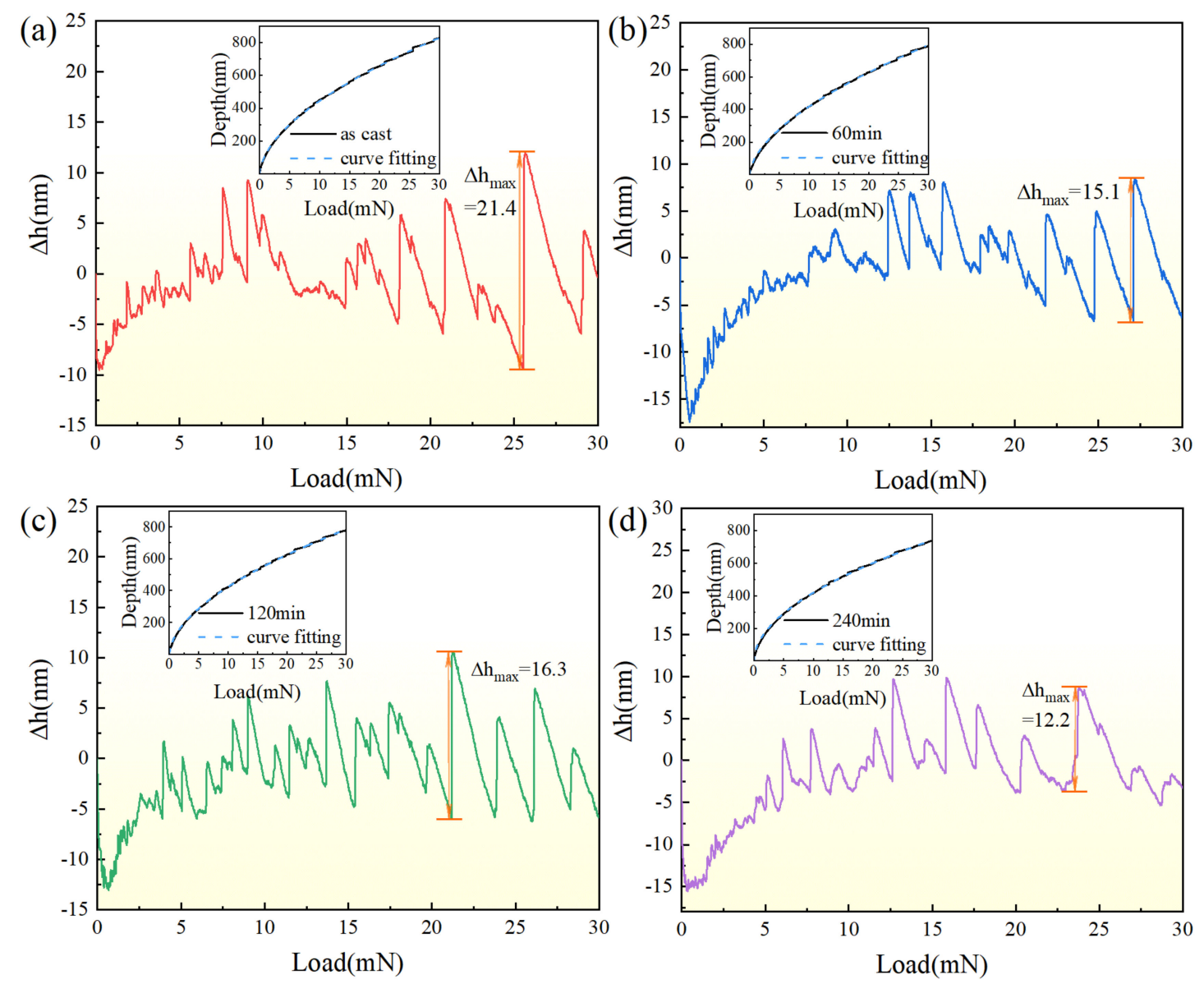

Figure 5. Variations of the length of serration $\Delta \mathrm{h}$ on the load at the loading stage for the as-cast and annealed $\mathrm{La}_{65} \mathrm{Al}_{14} \mathrm{Ni}_{5} \mathrm{Co}_{5} \mathrm{Cu}_{9.2} \mathrm{Ag}_{1.8}$ BMG and the fitted baseline for depth-load curve in the inset: (a) as-cast; (b) $60 \mathrm{~min}$; (c) $120 \mathrm{~min}$; (d) $240 \mathrm{~min}$.

The indentation morphology of the as-cast and annealed La-based BMGs shown in Figure $6 \mathrm{a}-\mathrm{d}$ presents that as the annealing time increases, the number of shear bands around the indentation decreases. The serrated flow behavior is always associated with the activation and propagation of single or multiple shear bands during plastic deformation. The liquid-like region containing a large amount of excess free volume is easy to form shear transformation zone (STZ) under the action of external force. The nucleation of shear band usually takes place in STZ. The annealed BMG undergoes structural relaxation, and the proportion of the liquid-like region decreases, so the degree of structural heterogeneity decreases and it is more difficult for the nucleation of shear band. Since plastic deformation is irrecoverable during nanoindentation, the plastically deformed BMG tends to flow in the opposite direction to the applied pressure, resulting in the accumulation around the indentation surface, corresponding to the area B shown in Figure 6e. With the increase of annealing time, the stacking area reflecting the ability of plastic deformation gradually decreases, which is consistent with the law described in Figure 4c. Otherwise, the partially enlarged view of area A indicated in Figure 6e shows that the maximum indentation depth of the annealed sample is smaller than that of the as-cast one, and once again confirms 
that the structural relaxation induced by the annealing leads to the hardening of La-based BMG.
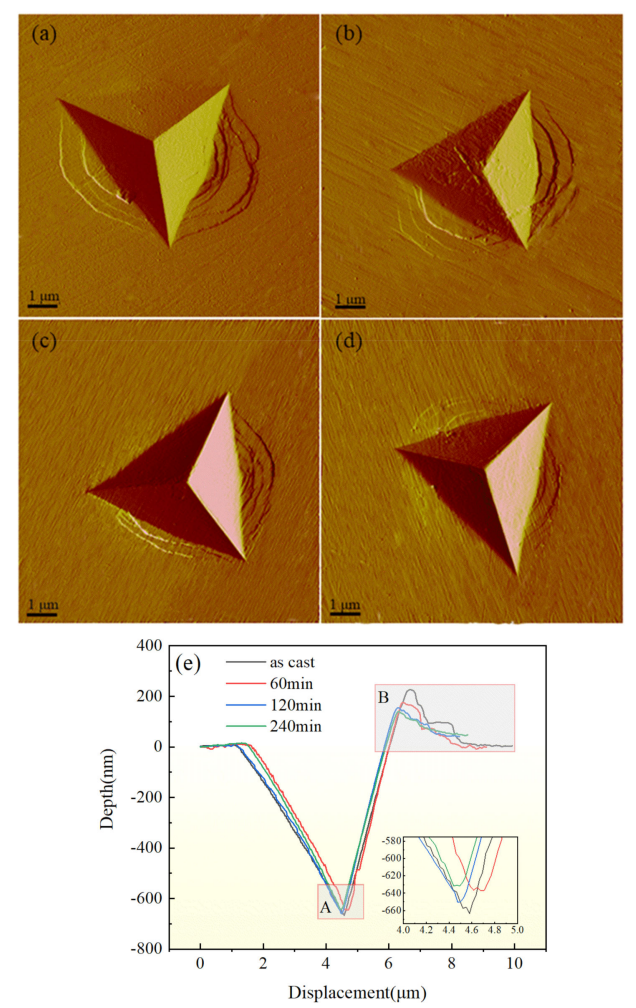

Figure 6. (a-d) Indentation morphology of the as-cast and annealed $\mathrm{La}_{65} \mathrm{Al}_{14} \mathrm{Ni}_{5} \mathrm{Co}_{5} \mathrm{Cu}_{9.2} \mathrm{Ag}_{1.8}$ BMG: (a) as-cast; (b) $60 \mathrm{~min}$; (c) $120 \mathrm{~min}$; (d) $240 \mathrm{~min}$; (e) Depth-displacement curves.

\section{Conclusions}

The effects of annealing temperature and time on thermal stability, enthalpy recovery, and nanomechanical behaviors of $\mathrm{La}_{65} \mathrm{Al}_{14} \mathrm{Ni}_{5} \mathrm{Co}_{5} \mathrm{Cu}_{9.2} \mathrm{Ag}_{1.8}$ BMG have been investigated by DSC and nanoindentation. When isochronous annealed at various temperatures from 373 to $403 \mathrm{~K}$ for $5 \mathrm{~min}$, the recovered enthalpy increases with the annealing temperature and reaches the maximum value at $403 \mathrm{~K}$. After being annealed in supercooled liquid region, the recovered enthalpy obviously decreases. When isothermal annealed at 393 $\mathrm{K}$ for various time, the recovery enthalpy of La-based BMG increases continuously and finally reaches saturation. The relation between the recovery enthalpy and annealing time can be well fitted by KWW function. With extending the isothermal annealing time, the hardness of La-based BMG increases but its plastic deformation ability declines, which can be attributed to the increase of the proportion of solid-like region and the enhancement of homogeneity. This work provides a promising route to develop La-based BMGs with enhanced mechanical and/or thermal properties.

Author Contributions: Conceptualization, S.L.; Investigation, T.S.; Writing—original draft, T.S.; Writing-review and editing, S.L. and L.H.; Supervision, S.L. and L.H. All authors have read and agreed to the published version of the manuscript.

Funding: This research received no external funding. This work was primarily financially supported by the National Natural Science Foundation of China (Grant No. 51871245) and National Key R\&D Program of China (Grant No. 2017YFE0301505).

Institutional Review Board Statement: Non applicable.

Informed Consent Statement: Non applicable. 
Data Availability Statement: The data presented in this article are available on request from the corresponding author.

Acknowledgments: This work was primarily financially supported by the National Natural Science Foundation of China (Grant No. 51871245), National Key R\&D Program of China (Grant No. 2017YFE0301505) and State Key Laboratory for Powder Metallurgy as well as Science and Technology on High Strength Structural Materials Laboratory, Central South University.

Conflicts of Interest: The authors declare no conflict of interest.

\section{References}

1. Egami, T.; Iwashita, T.; Dmowski, W. Mechanical properties of metallic glasses. Metals 2013, 3, 77-113. [CrossRef]

2. Chen, M. Mechanical Behavior of Metallic Glasses: Microscopic understanding of strength and ductility. Annu. Rev. Mater. Res. 2008, 38, 445-469. [CrossRef]

3. Wang, W.H. The elastic properties, elastic models and elastic perspectives of metallic glasses. Prog. Mater. Sci. 2012, 57, 487-656. [CrossRef]

4. Lin, C.Y.; Tien, H.Y.; Chin, T.S. Soft magnetic ternary iron-boron-based bulk metallic glasses. Appl. Phys. Lett. 2005, 86, 162501. [CrossRef]

5. Cheng, Y.Q.; Ma, E. Atomic-level structure and structure-property relationship in metallic glasses. Prog. Mater. Sci. 2011, 56, 379-473. [CrossRef]

6. Qiao, J.C.; Wang, Q.; Pelletier, J.M.; Kato, H.; Casalini, R.; Crespo, D.; Pineda, E.; Yao, Y.; Yang, Y. Structural heterogeneities and mechanical behavior of amorphous alloys. Prog. Mater. Sci. 2019, 104, 250-329. [CrossRef]

7. Puosi, F.; Jakse, N.; Pasturel, A. Dynamical, structural and chemical heterogeneities in a binary metallic glass-forming liquid. J. Phys. Condens Mat. 2018, 30, 145701. [CrossRef] [PubMed]

8. Wang, W.H. Dynamic relaxations and relaxation-property relationships in metallic glasses. Prog. Mater. Sci. 2019, 106, 100561. [CrossRef]

9. Ketov, S.V.; Ivanov, Y.P.; Şopu, D.; Louzguine-Luzgin, D.V.; Suryanarayana, C.; Rodin, A.O.; Schöberl, T.; Greer, A.L.; Eckert, J High-resolution transmission electron microscopy investigation of diffusion in metallic glass multilayer films. Mater. Today Adv. 2019, 1, 100004. [CrossRef]

10. Souza, C.A.C.; Ribeiro, D.V.; Kiminami, C.S. Corrosion resistance of Fe-Cr-based amorphous alloys: An overview. J. Non-Cryst. Solids 2016, 442, 56-66. [CrossRef]

11. Ramamurty, U.; Lee, M.L.; Basu, J.; Li, Y. Embrittlement of a bulk metallic glass due to low-temperature annealing. Scr. Mater. 2002, 47, 107-111. [CrossRef]

12. Huang, Y.J.; Ning, Z.L.; Shen, Z.; Liang, W.Z.; Sun, H.C.; Sun, J.F. Bending behavior of as-cast and annealed ZrCuNiAl bulk metallic glass. J. Mater. Sci. Technol. 2017, 33, 1153-1158. [CrossRef]

13. Zhang, P.N.; Li, J.F.; Hu, Y.; Zhou, Y.H. Microstructural evolution during annealing and rolling $\mathrm{Zr}_{52.5} \mathrm{Cu}_{17.9} \mathrm{Ni}_{14.6} \mathrm{Al}_{10} \mathrm{Ti}_{5}$ bulk metallic glass. Mater. Sci. Eng. A 2009, 499, 374-378. [CrossRef]

14. Zhang, Z.; Xia, L.; Wang, R.J.; Wei, B.C.; Pan, M.X.; Wang, W.H. Structural evolution and property changes in $\mathrm{Nd}_{60} \mathrm{Al}_{10} \mathrm{Fe}_{20} \mathrm{Co}_{10}$ bulk metallic glass during crystallization. Appl. Phys. Lett. 2002, 81, 4371-4373. [CrossRef]

15. Hua, N.B.; Liao, Z.L.; Wang, Q.T.; Zhang, L.; Ye, Y.X.; Brechtl, J.; Liaw, P.K. Effects of crystallization on mechanical behavior and corrosion performance of a ductile $\mathrm{Zr}_{68} \mathrm{Al}_{8} \mathrm{Ni}_{8} \mathrm{Cu}_{16}$ bulk metallic glass. J. Non-Cryst. Solids 2020, 529, 119782. [CrossRef]

16. Evenson, Z.; Busch, R. Enthalpy recovery and free volume relaxation in a $\mathrm{Zr}_{44} \mathrm{Ti}_{11} \mathrm{Ni}_{10} \mathrm{Cu}_{10} \mathrm{Be}_{25}$ bulk metallic glass. J. Alloys Compd. 2011, 509, S38-S41. [CrossRef]

17. Kanungo, B.P.; Glade, S.C.; Asoka-Kumar, P.; Flores, K.M. Characterization of free volume changes associated with shear band formation in $\mathrm{Zr}$ - and Cu-based bulk metallic glasses. Intermetallics 2004, 12, 1073-1080. [CrossRef]

18. Shi, H.Q.; Tang, C.C.; Zhao, X.Y.; Ding, Y.; Ma, L.Q.; Shen, X.D. Effect of isothermal annealing on mechanical performance and corrosion resistance of $\mathrm{Ni}$-free $\mathrm{Zr}_{59} \mathrm{Ti}_{6} \mathrm{Cu}_{17.5} \mathrm{Fe}_{10} \mathrm{Al}_{7.5}$ bulk metallic glass. J. Non-Cryst. Solids 2020, 537, 120013. [CrossRef]

19. Zhou, M.; Hagos, K.; Huang, H.Z.; Yang, M.; Ma, L.Q. Improved mechanical properties and pitting corrosion resistance of $\mathrm{Zr}_{65} \mathrm{Cu}_{17.5} \mathrm{Fe}_{10} \mathrm{Al}_{7.5}$ bulk metallic glass by isothermal annealing. J. Non-Cryst. Solids 2016, 452, 50-56. [CrossRef]

20. Jiang, Q.K.; Zhang, G.Q.; Chen, L.Y.; Wu, J.Z.; Zhang, H.G.; Jiang, J.Z. Glass formability, thermal stability and mechanical properties of La-based bulk metallic glasses. J. Alloys Compd. 2006, 424, 183-186. [CrossRef]

21. Qiao, J.C.; Chen, Y.H.; Casalini, R.; Pelletier, J.M.; Yao, Y. Main $\alpha$ relaxation and slow $\beta$ relaxation processes in a $\mathrm{La}_{30} \mathrm{Ce}_{30} \mathrm{Al}_{15} \mathrm{Co}_{25}$ metallic glass. J. Mater. Sci. Technol. 2019, 35, 982-986. [CrossRef]

22. Liang, D.D.; Wang, X.D.; Ge, K.; Cao, Q.P.; Jiang, J.Z. Annealing effect on beta-relaxation in a La-based bulk metallic glass. J. Non-Cryst. Solids 2014, 383, 97-101. [CrossRef]

23. Cui, X.; Qiao, J.C.; Li, J.J.; Meng, L.Z.; Guo, J.; Zu, F.Q.; Zhang, X.F.; Bian, B.C.; Zhang, Q.D.; Ma, Y.B. Room temperature activated slow $\beta$ relaxation and large compressive plasticity in a LaCe-based bulk metallic glass. Intermetallics 2020, 122, 106793. [CrossRef]

24. Cohen, M.; Grest, G. Liquid-glass transition, a free-volume approach. Phys. Rev. B 1979, 26, 6313-6314. [CrossRef]

25. Wang, J.F.; Liu, L.; Xiao, J.Z.; Zhang, T.; Wang, B.Y.; Zhou, C.L.; Long, W. Ageing behaviour of $\mathrm{Pd}_{40} \mathrm{Cu}_{30} \mathrm{Ni}_{10} \mathrm{P}_{20}$ bulk metallic glass during long-time isothermal annealing. J. Phys. D Appl. Phys. 2005, 38, 946-949. [CrossRef] 
26. Klement, W.K.; Willens, R.H.; Duwez, P. Non-crystalline Structure in Solidified Gold-Silicon Alloys. Nature 1960, 187, 869-870. [CrossRef]

27. Qiao, J.C.; Pelletier, J.M. Dynamic universal characteristic of the main ( $\alpha$ ) relaxation in bulk metallic glasses. J. Alloys Compd. 2014, 589, 263-270. [CrossRef]

28. Zhai, W.; Wang, C.H.; Qiao, J.C.; Pelletier, J.M.; Dai, F.P.; Wei, B. Distinctive slow $\beta$ relaxation and structural heterogeneity in (LaCe)-based metallic glass. J. Alloys Compd. 2018, 742, 536-541. [CrossRef]

29. Qiao, J.C.; Pelletier, J.M. Enthalpy relaxation in $\mathrm{Cu}_{46} \mathrm{Zr}_{45} \mathrm{Al}_{7} \mathrm{Y}_{2}$ and $\mathrm{Zr}_{55} \mathrm{Cu}_{30} \mathrm{Ni}_{5} \mathrm{Al}_{10}$ bulk metallic glasses by differential scanning calorimetry (DSC). Intermetallics 2011, 19, 9-18. [CrossRef]

30. Huang, Y.J.; Zhou, B.J.; Chiu, Y.L.; Fan, H.B.; Wang, D.J.; Sun, J.F.; Shen, J. The structural relaxation effect on the nanomechanical properties of a Ti-based bulk metallic glass. J. Alloys Compd. 2014, 608, 148-152. [CrossRef]

31. Yiu, P.; Jang, J.S.C.; Chang, S.Y.; Chen, Y.C.; Chu, J.P.; Hsue, C.H. Plasticity enhancement of Zr-based bulk metallic glasses by direct current electropulsing. J. Alloys Compd. 2012, 525, 68-72. [CrossRef]

32. Jiang, Q.K.; Nie, X.P.; Jiang, J.Z.; Deyneka-Dupriez, N.; Fecht, H.J. Room-temperature nanoindentation measurements of La-based bulk metallic glass. Scr. Mater. 2007, 57, 149-152. [CrossRef]

33. Zhang, M.; Wang, Y.J.; Dai, L.H. Understanding the serrated flow and Johari-Goldstein relaxation of metallic glasses. J. Non-Cryst. Solids 2016, 444, 23-30. [CrossRef] 